\title{
GAMBARAN PELAKSANAAN INISIASI MENYUSU DINI DI RUMAH SAKIT 'AISYIYAH MUNTILAN
}

\author{
THE IMPLEMENTATION OF EARLY BREASTFEEDING INITIATION \\ IN 'AISYIYAH MUNTILAN HOSPITAL
}

$\underline{\text { Nuli Nuryanti Zulala }}{ }^{1)}$, Sulistivaningsih ${ }^{2}$, Siti Arifah $^{3)}$

${ }^{122) 3)}$ Program Studi Ilmu Kebidanan Jenjang Diploma III, Universitas ‘Aisyiyah Yogyakarta

Email : nuli.zulala@unisayogya.ac.id

\begin{abstract}
ABSTRAK
Inisiasi menyusu Dini (IMD) merupakan intervensi sederhana yang mampu meningkatkan neonatal outcome secara signifikan yaitu mengurangi risiko kematian neonatal, sangat membantu dalam keberlangsungan pemberian ASI eksklusif dan periode lama menyusui. IMD dipengaruhi oleh sikap, pengetahuan dan motivasi bidan/dokter penolong persalinan, didukung oleh suami, keluarga, dan masyarakat. Penelitian ini menggunakan metode deskriptif observasional dengan rancangan cross sectional. Populasi penelitian ini adalah seluruh ibu bersalin pada bulan November sampai Desember 2016 di Rumah sakit 'Aisyiyah Muntilan. Teknik pengambilan sampel menggunakan non probability sampling dengan metode concevutive sampling sejumlah 72 sampel. Hasil penelitian menujukan 44\% pelaksanaan IMD dengan benar. Mayoritas pelaksanaan IMD dilaksanakan pada persalinan pervaginam (96.6\%), penangan petugas (bidan dan perawat) yang tepat (100\%), dukungan keluarga (90.6\%), usia kehamilan $\geq 37$ minggu (96.6\%) dan berat badan lahir $\geq 2500$ gram (87,5\%). Pelaksanaan IMD di Rumah Sakit 'Aisyiyah Muntilan belum berjalan dengan baik (44,4\%). Pelaksanaan IMD pada persalinan sectio caesaria sangat rendah (3,7\%) dan persalinan pervaginam $(68,9 \%)$
\end{abstract}

Kata kunci : IMD, persalinan pervaginam

\section{ABSTRACT}

Early Breastfeeding Initiation (EBI) is a simple intervention that is capable to improving neonatal outcomes i.e. significantly reduces the risk of neonatal death, greatly assist in the sustainability of exclusive breast feeding and long period of breastfeeding. EBI is influenced by attitudes, knowledge and motivation of midwife/doctor helper labor, supported by her husband, family, and community. This research uses descriptive observational method with cross sectional design. The population of this research is the whole birthing mothers in November to December 2016 in 'Aisyiyah Muntilan Hospital. Sampling techniques using non probability sampling with concevutive method of sampling a number of 72 samples. Results of research demonstrating the 44\% implementation of proper EBI. The majority of implementation of EBI carried out on vaginaly labor (96.6\%), proper care by midwives and nurses (100\%), family support (90.6\%), gestational age $\geq 37$ weeks (96.6\%) and birth weight $\geq 2500$ grams (87.5\%). The IMD implementation at 'Aisyiyah Muntilan Hospital has not gone well (44.4\%). Implementation of IMD in sectio caesaria is very low (3.7\%) and vaginal delivery (68.9\%)

Keywords : EBI, Vaginaly labor 


\section{PENDAHULUAN}

Ibu dan anak merupakan kelompok prioritas dalam penyelenggaraan upaya kesehatan, karena kesehatan ibu dan anak merupakan indikator keberhasilan pembangunan kesehatan suatu bangsa, Upaya pemeliharaan kesehatan anak ditujukan untuk mempersiapkan generasi mendatang yang sehat, cerdas, dan berkualitas serta untuk menurunkan angka kematian anak. Upaya ini dilakukan sejak janin masih dalam kandungan, dilahirkan, setelah dilahirkan, dan sampai berusia 18 (delapan belas) tahun. WHO merekomendasikan inisiasi menyusu dini (IMD) yaitu meletakkan bayi di dada ibu segera setelah lahir dengan metode skin to skin, kepala bayi diletakan diantara payudara ibu kemudian membiarkan bayi dengan nalurinya sendiri mencari papila mamae ibunya (Kemenkes, 2010).

IMD merupakan intervensi sederhana yang mampu meningkatkan neonatal outcome secara signifikan yaitu mengurangi risiko kematian neonatal (Edmond et al., 2006). IMD sangat membantu dalam keberlangsungan pemberian ASI eksklusif dan periode lama menyusui (Depkes, 2008). Penelitian di Ghana menyebutkan IMD dapat menyelamatkan $22 \%$ dari bayi yang meninggal sebelum usia satu bulan, IMD disebut sebagai tindakan penyelamatan kehidupan (Dyson et al., 2008). IMD merupakan kunci kesuksesan menyusui yang dipengaruhi oleh sikap, pengetahuan dan motivasi bidan/dokter penolong persalinan, didukung oleh suami, keluarga, dan masyarakat. Informasi dan dukungan sangat diperlukan bagi ibu dan keluarga dimulai sejak kehamilan (UNICEF, 2013; Debes et al., 2013).

$\begin{array}{llr}\text { Persalinan dengan } & \text { sectio } & \text { caesaria } \\ \text { menjadi penghalang } & \text { utama } & \text { dalam } \\ \text { pelaksanaan IMD, ibu menjadi kurang }\end{array}$

percaya diri untuk melakukan kontak kulit ke kulit dengan bayi serta efek dari anastesi yang menjadikan tertunda atau tidak terlaksananya IMD. Peningkatan kualitas asuhan antenatal serta upaya penurunan kejadian sectio caesaria tanpa indikasi merupakan langkah yang efektif dalam keberhasilan pelaksanaan IMD (Örün et al., 2010). Penyebab penundaan pelaksanaan IMD pada ibu paling sering terjadi pada persalinan sectio caesaria dan akibat kelelahan yang dialami ibu, penundaan pelaksanaan IMD mengakibatkan berkurangnya sekresi air susu ibu (Shwetal et al,. 2012).

Bayi baru lahir dengan sectio caesaria yang tidak dilakukan kontak kulit ke kulit dengan ibunya mengalami penurunan suhu $0,6^{\circ} \mathrm{C}$, penelitian oleh Horn et al. (2014) menunjukan 17 dari 21 bayi yang tidak dilakukan kontak kulit ke kulit menjadi hipotermi $\left(35,9^{\circ} \mathrm{C}\right)$ sedangkan 1 dari 19 bayi yang dilakukan kontak kulit ke kulit segera setelah lahir menjadi hipotermi. Penelitian Crenshaw (2014) menyatakan sebagian besar ibu yang menjalani persalinan dengan sectio caesaria dan melakukan IMD tidak menyadari proses jalannya pembedahan karena mereka terfokus pada bayi mereka, sehingga tidak ada bukti untuk menunda pelaksanaan IMD pada persalinan sectio caesaria.

PP No 33 Tahun 2012 tentang Pemberian Air Susu Ibu eksklusif, Pasal 9 menyebutkan Tenaga Kesehatan dan penyelenggara Fasilitas Pelayanan Kesehatan wajib melakukan IMD terhadap Bayi yang baru lahir kepada ibunya paling singkat selama 1 (satu) jam, pelanggaran terhadap aturan ini dikenakan sangsi mulai dari peringatan hingga pencabutan izin praktek. Bidan sesuai kewenangannya yang diatur dalam Permenkes No 369 tentang standar profesi bidan pada kompetensi ke 4 mengenai asuhan persalinan dan kelahiran bidan harus memiliki pengetahuan dasar 
transisi bayi baru lahir terhadap kehidupan diluar rahim, pemenuhan kebutuhan fisik BBL meliputi pernafasan, kehangatan, termasuk memfasilitasi IMD.

Gerakan rumah sakit sayang ibu dan bayi merupakan upaya pemerintah dalam menurunkan angka kematian ibu dan angka kematian neonatal melalui 10 langkah perlindungan ibu dan bayi secara terpadu dan pari purna, sehingga seluruh fasilitas kesehatan harus memfasilitasi setiap ibu melahirkan untuk melakukan IMD. IMD dan ASI eksklusif merupakan materi dalam KIE efektif dalam pelayanan antenatal terpadu yang bertujuan memenuhi hak setiap ibu hamil memperoleh pelayanan yang berkualitas sehingga mampu melalui kehamilan yang sehat, bersalin dengan selamat dan melahirkan bayi yang sehat dan berkualitas (Depkes, 2007; Depkes, 2009; Kemenkes, 2012; Kemenkes, 2015b)

Ikatan Bidan Indonesia (IBI) dalam prosedur Asuhan Persalinan Normal (APN) atau panduan dalam pertolongan persalinan fisiologis bagi bidan menetapkan mekanisme pencegahan hipotermi dan IMD sebagai asuhan sayang bayi pada langkah ke 26 dan 32 yaitu segera mengeringkan tubuh bayi mulai dari kepala sampai kaki kecuali tangan tanpa menghilangkan verniks serta segera mengganti kain basah dengan kain kering, kemudian menempatkan bayi untuk melakukan kontak kulit ke kulit dengan ibu dan membiarkannya selama 1 jam (Kemenkes, 2015a).

Cakupan IMD di Indonesia masih jauh dari target yaitu $80 \%$, cakupan IMD tahun 2013 sebesar 34,5\%, angka ini meningkat dari tahun $2010 \quad 29,3 \%$, sedangkan di Propinsi Jawa Tengah cakupan IMD tahun 2013 sebesar 37,5\%. Hasil studi pendahuluan berdasarkan wawancara dan melalui buku register bayi pada tanggal 9 Juni 2016 di Rumah Sakit 'Aisyiyah Muntilan bahwa pelaksanaan IMD sudah dilakukan sejak 2014, kebijakannya adalah semua bayi yang lahir spontan dengan kondisi ibu dan bayi sehat. Untuk persalinan dengan sectio caesaria pelaksanaan IMD baru dimulai tahun 2016, dalam pelaksanaannya masih ada bayi yang tidak dilakukan IMD dan sebagian besar bayi dibantu untuk menemukan puting ibu.

\section{METODE PENELITIAN}

Jenis penelitian ini adalah deskriptif observasional, penelitian ini mengamati ibu bersalin dalam pelaksanaan inisiasi menyusu dini dengan melihat hal yang berkaitan dengan pelaksanaan inisisi menyusu dini seperti penanganan petugas, dukungan suami, usia kehamilan, berat badan lahir bayi, cara persalinan dan lainnya (Sastroasmoro dan Ismael, 2014).

Populasi penelitian ini adalah seluruh ibu bersalin pada bulan November sampai Desember 2016 di Rumah sakit 'Aisyiyah Muntilan.

Kriteria inklusi penelitian yaitu seluruh ibu bersalin di Rumah sakit 'Aisyiyah Muntilan. Kriteria eksklusi penelitian yaitu ibu bersalin yang mengalami komplikasi seperti perdarahan, kejang.

Teknik pengambilan sampel dalam penelitian ini menggunakan non probability sampling dengan metode concecutive sampling yaitu mengambil subyek penelitian yang memenuhi kriteria inklusi sampai dengan kurun waktu tertentu sehingga jumlah sampel yang diperlukan terpenuhi.

Penentuan besar sampel menggunakan rumus:

$$
\mathrm{n}=\frac{\left\{\mathrm{Z}_{1-\alpha} \sqrt{2} \mathrm{P}(1-\mathrm{P})+\mathrm{Z}_{1-\mathrm{B}} \sqrt{ } \mathrm{P}_{1}\left(1-\mathrm{P}_{1}\right)+\mathrm{P}_{2}\left(1-\mathrm{P}_{2}\right)\right\}^{2}}{\left(\mathrm{P}_{1}-\mathrm{P}_{2}\right)^{2}}
$$

Keterangan :

$\mathrm{Z}_{1-\alpha} \quad=$ Level of significance, $\alpha=0,05=$ 1,96

$Z_{1-\beta}=$ Power of the test $80 \%=0,84$ 
$\mathrm{P}_{2}=$ Proporsi keberhasilan IMD 0,37

(Bapenas Kemenkes, 2013)

$\mathrm{RR}=2$ (Thukral et al., 2012)

$\mathrm{P}_{1}=0,74\left(\mathrm{P}_{1}=\mathrm{RR} \times \mathrm{PP}_{2}\right)$

Berdasarkan perhitungan rumus besar sampel bahwa jumlah sampel yang yang diperoleh adalah 66 dan dilakukan penambahan responden sebanyak $10 \%$ untuk mengantisipasi kemungkinan terjadinya subyek penelitian yang terpilih drop out maka keseluruhan jumlah sampel menjadi 72 responden.

Rangkuman penentuan dan penetapan sampel dalam penelitian sebagai berikut :

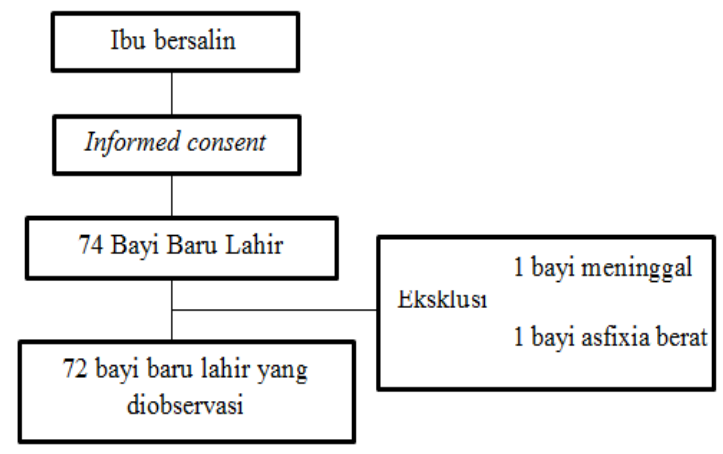

Gambar 1. Rangkuman Penelitian

\section{Instrumen Penelitian}

1. Lembar kuisioner demografi responden Lembar kuisioner demografi ini berisikan identitas responden yang terdiri dari nama, usia ibu, status obstetri, alamat, umur kehamilan, alamat, cara persalinan, berat badan ibu, berat badan bayi.

2. Lembar observasi pelaksanaan IMD

Lembar observasi ini untuk memantau pelaksanaan IMD menggunakan langkah yang mengacu pada buku Panduan Operasional Pelayanan Persalinan dan Nifas Normal Bagi tenaga Kesehatan, kemenkes 2015.

\section{HASIL DAN PEMBAHASAN}

1. Karakteristik Responden

Karakteristik responden bayi mayoritas memiliki berat badan $\geq 2500$ gram dan berjenis kelamin laki-laki. Pada karakteristik ibu mayoritas umur kehamilan $\geq 37$ minggu, cara persalinan dengan pervaginam, berusia 20-35 tahun dengan status obstetrik multipara, pendidikan SLTA serta pekerjaan IRT.

Tabel 1. Karakteristik Responden

\begin{tabular}{|c|c|c|}
\hline Karakteristik & $\begin{array}{l}\text { Jumlah } \\
(\mathrm{n}=72)\end{array}$ & $\begin{array}{l}\text { Prosentase } \\
(\%)\end{array}$ \\
\hline \multicolumn{3}{|l|}{ Karakteristik bayi } \\
\hline \multicolumn{3}{|l|}{ Berat lahir bayi } \\
\hline 2000 - 2499 gram & 5 & 6,9 \\
\hline$\geq 2500$ gram & 67 & 93,1 \\
\hline \multicolumn{3}{|l|}{ Jenis kelamin bayi } \\
\hline Laki-laki & 41 & 56,9 \\
\hline Perempuan & 31 & 43,1 \\
\hline \multicolumn{3}{|l|}{ Karakteristik ibu } \\
\hline \multicolumn{3}{|l|}{ Umur kehamilan } \\
\hline$<37$ minggu & 2 & 2,8 \\
\hline$\geq 37$ minggu & 70 & 97,2 \\
\hline \multicolumn{3}{|l|}{ Cara persalinan } \\
\hline Sectio caesaria & 27 & 37,5 \\
\hline Pervaginam & 45 & 62,5 \\
\hline \multicolumn{3}{|l|}{ Usia ibu } \\
\hline$<20$ atau $>35$ tahun & 14 & 19,4 \\
\hline $20-35$ tahun & 58 & 80,6 \\
\hline \multicolumn{3}{|l|}{ Status obstetric } \\
\hline Primipara & 26 & 36,1 \\
\hline Multipara & 46 & 63,9 \\
\hline \multicolumn{3}{|l|}{ Pendidikan ibu } \\
\hline SD & 3 & 4,2 \\
\hline SLTP & 9 & 12,5 \\
\hline SLTA & 39 & 54,2 \\
\hline D3 & 9 & 12,5 \\
\hline $\mathrm{S} 1$ & 11 & 15,3 \\
\hline $\mathrm{S} 2$ & 1 & 1,3 \\
\hline \multicolumn{3}{|l|}{ Pekerjaan } \\
\hline Guru & 4 & 5,6 \\
\hline IRT & 34 & 47,2 \\
\hline Petani & 3 & 4,2 \\
\hline PNS & 1 & 1.3 \\
\hline Swasta & 25 & 34.7 \\
\hline Wiraswasta & 5 & 7,0 \\
\hline
\end{tabular}

2. Pelaksanaan IMD

Pelaksanaan IMD dikatakan tepat apabila sesuai dengan langkah yang ditetapkan oleh WHO dan Kemenkes. 
Tabel 2. Pelaksanaan IMD

\begin{tabular}{|c|c|c|c|}
\hline No & Kegiatan & $\mathbf{n}$ & $\%$ \\
\hline 1 & $\begin{array}{l}\text { Membersihkan tubuh bayi tanpa } \\
\text { membersihkan verniks }\end{array}$ & & \\
\hline $\mathrm{a}$ & $\begin{array}{l}\text { Meletakan kain kering dan hangat diatas } \\
\text { perut ibu }\end{array}$ & 45 & 62,5 \\
\hline b & $\begin{array}{l}\text { Melakukan penilaian selintas dan } \\
\text { meletakkan bayi diatas perut ibu }\end{array}$ & 45 & 62,5 \\
\hline $\mathrm{c}$ & $\begin{array}{l}\text { Mengeringkan bayi mulai dari muka, } \\
\text { kepala dan bagian tubuh lainnya kecuali } \\
\text { bagian tangan tanpa membersihkan verniks }\end{array}$ & 72 & 100 \\
\hline d & $\begin{array}{l}\text { Segera mengganti handuk basah dengan } \\
\text { handuk atau kain yang kering }\end{array}$ & 72 & 100 \\
\hline 2 & Melakukan kontak kulit ibu ke kulit bayi & & \\
\hline $\mathrm{a}$ & $\begin{array}{l}\text { Meletakkan bayi di dada atau perut ibu } \\
\text { dalam posisi telungkup agar ada kontak } \\
\text { kulit ibu ke kulit bayi, }\end{array}$ & 46 & 63,8 \\
\hline b & $\begin{array}{l}\text { Melakukan kontak kulit ke kulit selama } \\
\text { minimal } 1 \text { jam }\end{array}$ & 32 & 44,4 \\
\hline 3 & $\begin{array}{l}\text { Membiarkan bayi mencari puting } \\
\text { ibunya tanpa intervensi }\end{array}$ & 46 & 63,9 \\
\hline
\end{tabular}

Berdasarkan hasil penelitian tabel 2, pelaksanaan IMD belum berjalan dengan optimal. Langkah I membersihkan tubuh bayi tanpa membersihkan vernik hanya pada proses mengeringkan bayi dan mengganti handuk basah dengan handuk kering yang dilakukan sempurna, meletakan kain kering dan hangat diatas perut ibu serta melakukan penilaian selintas dan meletakan bayi diatas perut ibu terhalang pada persalinan dengan sectio caesaria. Dalam proses langkah II melakukan kontak kulit ibu ke kulit bayi selama minimal 1 jam masih sangat rendah, dimana proses ini merupakan tolak ukur dalam keberhasilan IMD.

IMD merupakan intervensi sederhana yang mampu meningkatkan neonatal outcome secara signifikan yaitu mengurangi risiko kematian neonatal, membantu dalam keberlangsungan pemberian ASI eksklusif dan periode lama menyusui. Penelitian di Ghana menyebutkan IMD dapat menyelamatkan $22 \%$ dari bayi yang meninggal sebelum usia satu bulan, menunda pelaksanaan IMD dalam pencegahan hipotermi pada bayi baru lahir meningkatkan 6 kali risiko kematian neonatal (Edmond et al., 2006; Dyson et al., 2008; Depkes, 2008; Roesli, 2008).

Jumlah petugas kesehatan yang berkaitan langsung dengan pelaksanaan IMD perlu dipertimbangkan, mengingat perbandingan jumlah pasien dengan petugas jaga tidak seimbang dikala banyaknya pasien baru datang dan ruang bersalin sibuk, sehingga petugas merasa kelelahan ataupun bersamaan dengan kunjungan dokter anak yang menjadikan petugas tidak mampu menunggu kontak kulit ke kulit antara ibu dan bayi selama minimal 1 jam. Perlunya petugas perawat bayi pada instalasi bedah sentral untuk memastikan pelaksanaan IMD pada proses persalinan dengan sectio caesaria dapat berjalan dengan baik.

Temuan USAID-KINERJA tahun 2014, kegagalan IMD serta ASI Eksklusif karena kurangnya pengetahuan mengenai manfaat dari IMD dan ASI Eksklusif sedangkan dari sisi pemberi layanan hambatan yang muncul adalah rendahnya anggaran yang mendukung program, bervariasinya komitmen, pemahama dan kesadaran tenaga kesehatan, terbatasnya waktu dan sarana petugas dalam memberikan konseling, gencarnya promosi susu formula, fasilitas yang belum memadai serta kurangnya pengawasan terhadap petugas (USAID and KINERJA, 2014).

Petugas kesehatan memiliki peran yang sangat penting dalam pelaksanaan IMD yang dipengaruhi oleh sikap, pengetahuan dan motivasi serta didukung oleh suami, keluarga, dan masyarakat. Informasi dan dukungan sangat diperlukan bagi ibu dan keluarga dimulai sejak kehamilan sedangkan dukungan tenaga kesehatan melalui pemberian KIE, sosialisasi serta media berupa leaflet, banner merupakan faktor yang paling memperkuat keberhasilan pelaksanaan IMD (Fikawati dan Syafiq, 2009; Kemenkes, 2012b; Nahidi et al., 2013; Mujiati dan Novianti, 2015; UNICEF, 2013; Debes et al., 2013). 
Dukungan bidan dan tenaga
kesehatan sangat penting dalam implementasi IMD, penelitian Syam dan Amiruddin (2015) menunjukkan bahwa ibu yang memperoleh dukungan dari bidan dan tenaga kesehatan memiliki tingkat keberhasilan melakukan IMD 17.5 kali lebih besar dari ibu yang tidak mendapatkan dukungan dari bidan dan tenaga kesehatan. Tenaga kesehatan memiliki tanggung jawab dan peran yang penting dalam melaksanakan IMD sebagai intervensi mencegah hipotermi sehingga dapat meningkatkan neonatal outcome (Mizzi and Muskat, 2007).

Komunikasi efektif merupakan kunci keberhasilan pelaksanaan IMD, komunikasi ini meliputi komunikasi antara petugas, pasien dan tim kesehatan lain baik pada proses persalinan normal maupun sectio caesaria (Hung and Berg, 2011).

3. Faktor Yang Mendukung Keberhasilan IMD

Tabel 3. Faktor Yang Mendukung Keberhasilan IMD

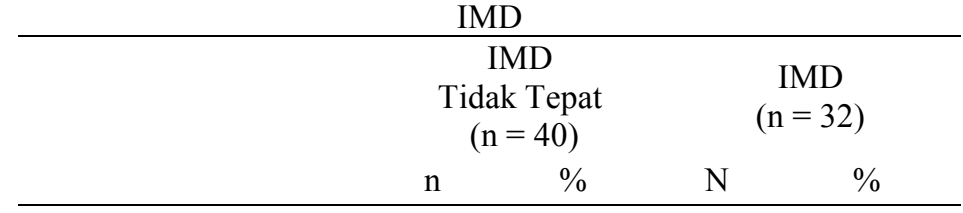

\begin{tabular}{lllll}
\hline Cara Persalinan & & & & \\
SC & 26 & 65 & 1 & 3,1 \\
$\begin{array}{l}\text { Pervaginam } \\
\text { Penanganan Petugas }\end{array}$ & 14 & 35 & 31 & 96,9 \\
$\begin{array}{l}\text { Tidak Tepat } \\
\text { Tepat }\end{array}$ & 40 & 100 & 0 & 0 \\
$\begin{array}{l}\text { Dukungan Keluarga } \\
\text { Tidak }\end{array}$ & 0 & 0 & 32 & 100 \\
$\begin{array}{l}\text { Ada } \\
\text { Umur Kehamilan }\end{array}$ & 15 & 37,5 & 29 & 90,6 \\
$<37$ minggu & 1 & 2,5 & 1 & 3,1 \\
$\geq 37$ Minggu & 39 & 97,5 & 31 & 96,9 \\
Berat Badan Lahir & & & & \\
$<2500$ gram & 1 & 2,5 & 4 & 12,5 \\
$\geq 2500$ gram & 39 & 97,5 & 28 & 87,5 \\
\hline
\end{tabular}

a. Cara Persalinan
Cara persalinan berpengaruh terhadap pelaksanaan IMD. Pelaksanaan IMD yang tepat pada persalinan dengan sectio caesaria 3,7\% (1 dari 27) dan 68,9\% pada persalinan pervaginam.

Hasil ini sejalan dengan penelitian Orun et al., 2010 dan Shwetal et al,. 2012, yang menyatakan bahwa persalinan dengan sectio caesaria menjadi penghalang utama dalam pelaksanaan IMD, ibu menjadi kurang percaya diri untuk melakukan kontak kulit ke kulit dengan bayi serta efek dari anastesi yang menjadikan tertunda atau tidak terlaksananya IMD. Penyebab penundaan pelaksanaan IMD pada ibu paling sering terjadi pada persalinan sectio caesaria dan akibat kelelahan yang dialami ibu, penundaan pelaksanaan IMD mengakibatkan berkurangnya sekresi air susu ibu

Penelitian Crenshaw (2014) menyatakan sebagian besar ibu yang menjalani persalinan dengan sectio caesaria dan melakukan IMD tidak menyadari proses jalannya pembedahan karena mereka terfokus pada bayi mereka, sehingga tidak ada bukti untuk menunda pelaksanaan IMD pada persalinan sectio caesaria.

Pemerintah telah memberikan pedoman melalui Peraturan Pemerintah No 33 Tahun 2012 tentang pemberian Air Susu Ibu Eksklusif, pada Pasal 9 disebutkan tenaga kesehatan dan penyelenggara fasilitas pelayanan kesehatan wajib melakukan Inisiasi Menyusu Dini (IMD) terhadap bayi yang baru lahir kepada ibunya paling singkat selama 1 (satu) jam, dengan cara meletakan bayi secara tengkurap di dada atau perut ibu sehingga kulit bayi melekat pada kulit ibu. Pada Pasal 10 disebutkan tenaga kesehatan dan fasilitas pelayanan kesehatan wajib menempatkan ibu dan bayi dalam 1 ruangan atau rawat gabung kecuali atas indikasi medis, penempatan tersebut dimaksudkan untuk memudahkan pemberian ASI Ekslusif. Pasal 13 menyebutkan tenaga 
kesehatan dan penyelenggara fasilitas kesehatan wajib memberikan informasi dan edukasi mengenai ASI Eksklusif kepada ibu adan atau anggota keluarga sejak pemeriksaan kehamilan hingga periode pemberian ASI Eksklusif selesai (Kemenkes, 2012b).

\section{b.Penanganan Petugas}

Penanganan petugas yang tepat dalam pelaksanaan IMD pada tabel 2 meliputi belum terlaksana dengan baik terutama pada proses persalinan dengan section caesaria.

Asuhan Persalinan Normal (APN) atau panduan dalam pertolongan persalinan fisiologis bagi bidan menetapkan mekanisme pencegahan hipotermi dan IMD sebagai asuhan sayang bayi pada langkah ke 26 dan 32 yaitu segera mengeringkan tubuh bayi mulai dari kepala sampai kaki kecuali tangan tanpa menghilangkan verniks serta segera mengganti kain basah dengan kain kering, kemudian menempatkan bayi untuk melakukan kontak kulit ke kulit dengan ibu dan membiarkannya selama 1 jam (Kemenkes, 2015a). Menunda pelaksanaan IMD dalam pencegahan hipotermi pada bayi baru lahir meningkatkan 6 kali risiko kematian neonatal, menyusu pada satu jam pertama menyelamatkan satu juta nyawa bayi (Roesli, 2008).

Petugas kesehatan berperan besar dalam pelaksanaan IMD melalui kontak kulit ke kulit antara ibu dan bayi segera setelah lahir selama minimal 1 jam (WHO, 1997).

c.Dukungan

25 responden $(62,5 \%)$ yang tidak mendapatkan dukungan dari keluarga berupa pendampingan selama proses persalinan tidak dilakukan IMD.

Komunikasi dan promosi merupakan bagian dari keberhasilan pelaksanaan IMD, dalam Kepmenkes No 369 Tahun 2007 mengenai Standar Profesi Bidan disebutkan bidan harus memiliki kompetensi mengenai promosi IMD dan menyusui sejak kehamilan, saat persalinan, segera setelah persalinan dan periode nifas. Dukungan bidan dan tenaga kesehatan sangat penting dalam implementasi IMD, penelitian Syam Azniah dan Amiruddin Ridwan menunjukkan bahwa ibu yang memperoleh dukungan dari bidan dan tenaga kesehatan memiliki tingkat keberhasilan melakukan IMD 17.5 kali lebih besar dari ibu yang tidak mendapatkan dukungan dari bidan dan tenaga kesehatan (Syam dan Amiruddin, 2015).

Penerapkan Asuhan sayang ibu dan bayi merupakan dukungan fasilitas pelayanan kesehatan yang mampu meningkatkan pelaksanaan IMD dan kesuksesan menyusui.

Media dukungan terhadap IMD seperti leaflet dan poster serta penyuluhan rutin oleh petugas kesehatan mampu meningkatkan keberhasilan IMD (Mujiati \& Novianti, 2015)

d.Umur Kehamilan

Tiap tahun terdapat 15 juta kelahiran prematur 1 dari 10 kelahiran di dunia, 1,1 juta diantaranya meninggal karena komplikasi, Indonesia menempati urutan ke 9 dengan 675.700 kelahiran prematur per tahun $(15,5 \%)$, bayi prematur rentan terhadap komplikasi jantung, paru-paru, gastrointestinal, metabolisme tubuh dan imunitas serta bermasalah dalam pengaturan suhu tubuh karena sedikitnya cadangan lemak dalam tubuh juga memiliki risiko anemia dan hiperbilirubin (WHO, 2012).

IMD lebih efektif untuk mengurangi risiko hipotermi pada bayi prematur dibandingkan menggunakan inkubator (McCall et al., 2010). Bayi baru lahir memiliki risiko kehilangan panas tubuh, terutama bayi prematur, luas permukaan bayi baru lahir 2,7 kali lebih besar dari berat badannya, sedangkan bayi prematur memiliki luas permukaan 4 kali lebih besar 
dari berat badannya dibandingkan dengan orang dewasa (Lunze et al., 2013). Bayi prematur sangat berisiko menjadi hipotermia dan sangat memerlukan pertahanan hemostasis suhu tubuh dan lingkungan, kehilangan panas karena penguapan (evaporasi) yang disebabkan karena masih lemahnya fungsi kulit serta rasio luas permukaan tubuh bayi lebih besar dan termoregulasi pada bayi prematur sangat lemah maka bayi prematur perlu untuk mendapatkan panas dari lingkungan untuk menghindari hipotermia dan stes dingin (Karlsson et al., 2012).

e.Berat Badan Lahir

Pada penelitian ini terdapat $5(7 \%)$ bayi lahir dengan berat $<2500$ gram. 4 responden dilakukan IMD dengan tepat serta 1 responden tidak dilakukan IMD dengan tepat.

Bayi BBLR (berat badan lahir rendah) yang tidak dilakukan IMD memiliki risiko 2,9 kali terjadi kematian neonatal dari pada bayi BBLR yang dilakukan IMD (Berkat and Sutan, 2014). Bayi dengan berat badan rendah memiliki kesulitan untuk mempertahankan suhu tubuh karena peningkatan hilangnya panas, kurangnya lemak sub kutan, rasio luas permukaan terhadap berat badan serta produksi panas berkurang akibat lemak coklat yang tidak memadai serta ketidakmampuan untuk menggigil (Kosim et al., 2014).

\section{SIMPULAN}

Pelaksanaan IMD di Rumah Sakit 'Aisyiyah Muntilan belum berjalan dengan baik (44,4\%). Pelaksanaan IMD pada persalinan sectio caesaria sangat rendah $(3,7 \%)$ dan persalinan pervaginam $(68,9 \%)$.

\section{DAFTAR PUSTAKA}

Bapenas Kemenkes. (2013). Riset Kesehatan Dasar Tahun 2013.

Debes, A. K., Kohli, A., Walker, N., Edmond, K., \& Mullany, L. C. (2013).
Time to Initiation of Breastfeeding and Neonatal Mortality and Morbidity : a Systematic Review. BMC Public Health, 13(Suppl 3). Retrieved from http://www.biomedcentral.com/14712458/13/S3/S19REVIEW

Depkes. (2007). Kepmenkes No 369 tahun 2007 tentang Standar Profesi Bidan.

Depkes. (2008). Inisiasi Menyusu Dini (IMD) dan ASI Eksklusif 6 Bulan.

Depkes. (2009). Pedoman Pelaksanaan Program Rumah Sakit Sayang Ibu dan Bayi.

Dyson, L., Mccormick, F., \& Renfrew, M. (2008). Interventions for promoting the initiation of breastfeeding ( review ).

Cochrane Database of Systematic

Reviews, (2). http://doi.org/10.1002/14651858.CD00 1688.pub2.www.cochranelibrary.com

Edmond, K. M., Zandoh, C., Quigley, M. A., Amenga-etego, S., \& Owusu-agyei, S. (2006). Delayed breastfeeding initiation increases risk of neonatal mortality. Pediatrics, 117(3). http://doi.org/10.1542/peds.2005-1496

Fikawati, S., \& Syafiq, A. (2009). Penyebab Keberhasilan dan Kegagalan Praktik Pemberian ASI Eksklusif. Jurnal Kesehatan Masyarakat Nasional, 4, 120-131.

Hung, K. J., \& Berg, O. (2011). Early Skin to Skin After Cesarean To Improve Breastfeeding. NMC, 36(5), 318-324. http://doi.org/10.1097/NMC.0b013e31 82266314

Kemenkes. (2010). Buku Saku Pelayanan Kesehatan Neonatal Esensial.

Retrieved from http://www.gizikia.depkes.go.id/wpcontent/uploads/downloads/2011/09/Bu ku-Saku-Pelayanan-KesehatanNeonatal-Esensial.pdf

Kemenkes. Peraturan Pemerintan No 33 Tahun 2012 Tentang Pemberian ASI Eksklusif (2012). 
Kemenkes. (2012b). PP No 33 Tahun 2012

Tentang Pemberian Air Susu Ibu Eksklusif. Retrieved from http://www.kinerja.or.id/pdf/5dffecb94ca6-4e08-83de-2d4bb555d08f.pdf

Kemenkes. (2015a). Panduan Operasional Pelayanan Persalinan dan Nifas Normal Bagi Tenaga Kesehatan. Jakarta.

Kemenkes. (2015b). Pedoman Pelayanan Antenatal Terpadu. Jakarta.

Mizzi, J., \& Muskat, R. V. (2007). Hypothermia in the early neonatal period : follow-up study. Malta Medical Journal, 19(1).

Mujiati, \& Novianti. (2015). Pelaksanaan Sosialisasi Inisiasi Menyusu Dini ( IMD ) di Rumah Sakit St Carolus dan Rumah Sakit Umum Daerah ( RSUD ) Budhi Asih Jakarta. Buletin Penelitian Kesehatan, 43(4), 247-256.

Nahidi, F., Tavafian, S. S., \& Haidarzade, M. (2013). Midwifes ' Opinions about Reinforcing Factors in Skin to Skin Contact, Immediately After Delivery: A Descriptive Study. Health Education $\&$ Health Promotion, 1(2).

Orün, E., Yalç, S. S., Madenda, Y., \& Üstünyurt-eras, Z. (2010). Factors associated with breastfeeding initiation time in a Baby-Friendly Hospital. The Turkish Journal Of Pediatrics, 52, 1016.

Roesli, U. (2008). Inisiasi Menyusu Dini Plus ASI Eksklusif. Jakarta: Pustaka Bunda.

Sastroasmoro, S., \& Ismael, S. (2014). Dasar-dasar Metodologi Penelitian Klinis Edisi Ke-5. Sagung Seto.

Shwetal, B., Pooja, P., Neha, K., Amit, D., \& Rahul, P. (2012). Knowledge, Attitude And Practice Of Postnatal Mothers For Early Initiation Of Breast Feeding In The Obstetric Wards Of A Tertiary Care Hospital Of Vadodara City. National Journal Of Community
Medicine, 3(2), 305-309.

Syam, A., \& Amiruddin, R. (2015). Inhibitor Factors of Early Initiation of Breastfeeding among Mothers in Rural District Bone, South Sulawesi, Indonesia. Asian Journal Of Epidemiology. http://doi.org/10.3923/aje.2015.1.8

Thukral, A., Sankar, M. J., Agarwal, R., Gupta, N., Daeorari, A., \& Paul, V. (2012). Early Skin-to-Skin Contact and Breast-Feeding Behavior in Term Neonates : A Randomized Controlled Trial. Neonatology, 102, 114-119. http://doi.org/10.1159/000337839

UNICEF. (2013). The Evidence and Rationale for the UNICEF UK Baby Friendly Initiative Standards. Retrieved from https://www.unicef.org.uk/wpcontent/uploads/sites/2/2013/09/baby_f riendly_evidence_rationale.pdf

USAID, \& KINERJA. (2014). Tata Kelola Inisiasi Menyusu Dini Dan Asi Eksklusif. 